\title{
Circuit
}

Musiques contemporaines

\section{Les illustrations}

\section{Cal Schenkel}

Volume 14, numéro 3, 2004

Frank Zappa : 10 ans après

URI : https://id.erudit.org/iderudit/902331ar

DOI : https://doi.org/10.7202/902331ar

Aller au sommaire du numéro

\section{Éditeur(s)}

Les Presses de l'Université de Montréal

ISSN

1183-1693 (imprimé)

1488-9692 (numérique)

Découvrir la revue

Citer ce document

(2004). Les illustrations : Cal Schenkel. Circuit, 14(3), 113-114.

https://doi.org/10.7202/902331ar

Ce document est protégé par la loi sur le droit d'auteur. L'utilisation des services d'Érudit (y compris la reproduction) est assujettie à sa politique d'utilisation que vous pouvez consulter en ligne.

https://apropos.erudit.org/fr/usagers/politique-dutilisation/
Cet article est diffusé et préservé par Érudit.

Érudit est un consortium interuniversitaire sans but lucratif composé de l’Université de Montréal, l'Université Laval et l'Université du Québec à Montréal. Il a pour mission la promotion et la valorisation de la recherche. https://www.erudit.org/fr/ 


\section{LES ILLUSTRATIONS}

Cal Schenkel est bien connu pour ses diverses collaborations en art visuel avec Frank Zappa (nombreuses illustrations pour des pochettes de disque, notamment). De la classique parodie du «Sergeant Pepper's Lonely Hearts Club Band " des Beatles pour l'album «We're Only in It for the Money" (1968) jusqu'à la compilation "Son of Cheap Thrills» (1999). II cite parmi ses pochettes préférées celles des disques "Cruising With Ruben \& The Jets", "Uncle Meat", "Burnt Weeny Sandwich", "The Grand Wazoo " et "One Size Fits All ». Calvin a aussi collaboré au niveau graphique avec de nombreux artistes parmi lesquels on compte Tom Waits, Don Van Vliet (Captain Beefheart), Dion \& The Belmonts ou Three Dog Night. Son talent s'exprime à travers différents médias, de l'habillage de disques compacts et de cassettes vidéos jusqu'à l'animation cinématographique et télévisuelle. Aujourd'hui, ses activités principales sont la peinture et l'édition en tirages limités.

La majorité des illustrations de ce numéro sont extraites de ces cahiers de croquis et constituent des versions préliminaires de projets en cours.

Pour plus de détails sur Cal Schenkel, son œuvre, des indices secrets et plus encore, visitez son site Internet à l'adresse www.ralf.com. 


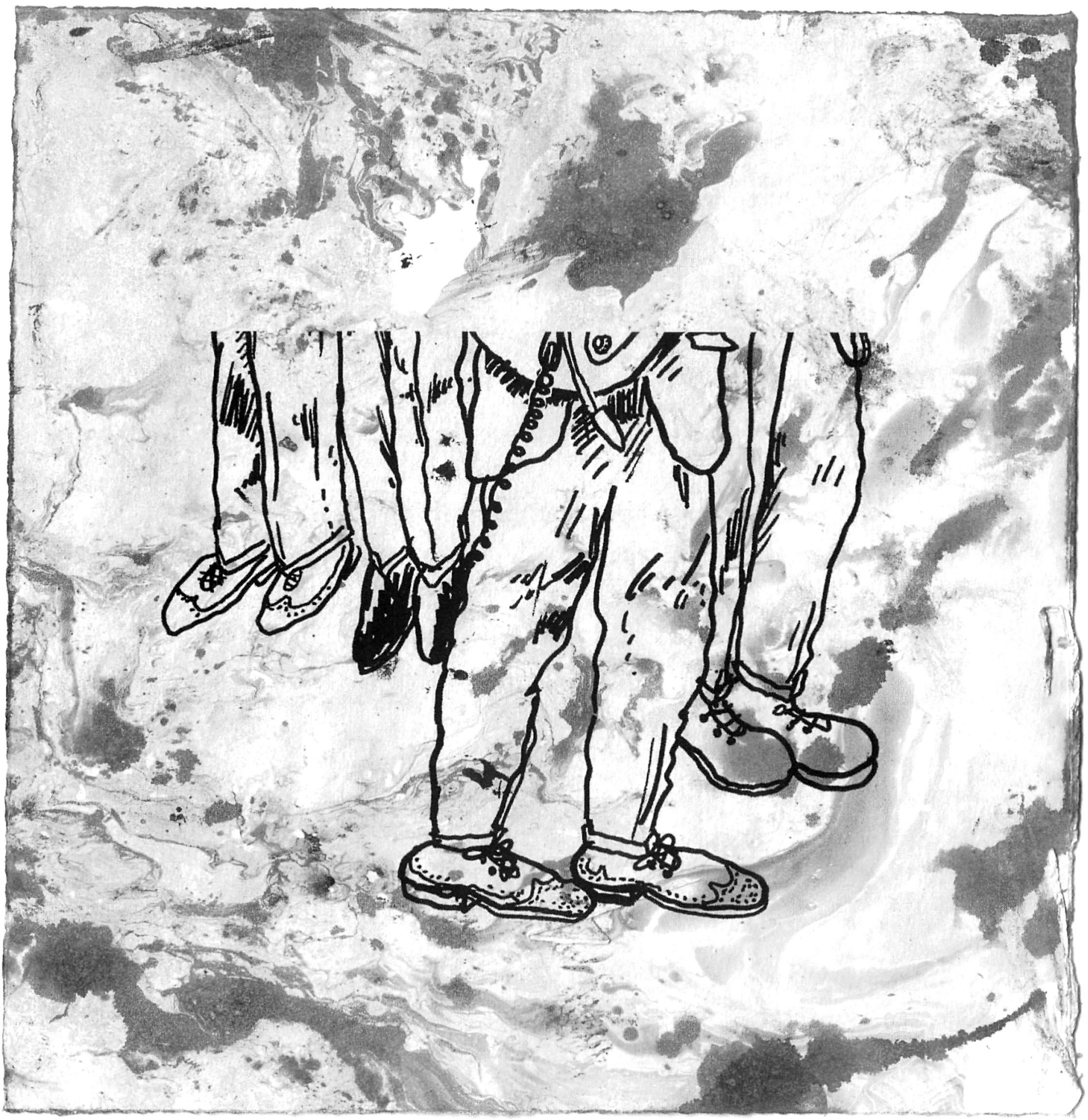

